\title{
June 2019 Pulmonary Case of the Month: Try, Try Again
}

\author{
Lewis J. Wesselius, MD \\ Department of Pulmonary Medicine \\ Mayo Clinic Arizona \\ Scottsdale, AZ USA
}

\section{History of Present IIIness}

A 53-year-old woman from presented with a 3-year history of shortness of breath. She was diagnosed with pneumonia in 2016, but even after treatment with antibiotics, continued to require supplemental oxygen. A CT-guided biopsy of a lung nodule was performed but there were no diagnostic findings. A surgical lung biopsy at another hospital was done but the report is unavailable. She had been diagnosed with possible scleroderma and treated with mycophenolate for 3 months and then azathioprine.

\section{Past Medical History, Social History and Family History}

Aside from her history as in the HPI she has a remarkably negative past medical history. She does not smoke. Family history is noncontributory.

\section{Physical Examination}

- HEENT: negative

- Chest: Fine crackles at both lung bases

- Cardiovascular: regular rhythm, no murmur

- Skin: skin thickening on fingers and distal forearms, but not elsewhere. No pitting, ulcerations or calcinosis

\section{Radiology}

A chest x-ray was performed (Figure 1).

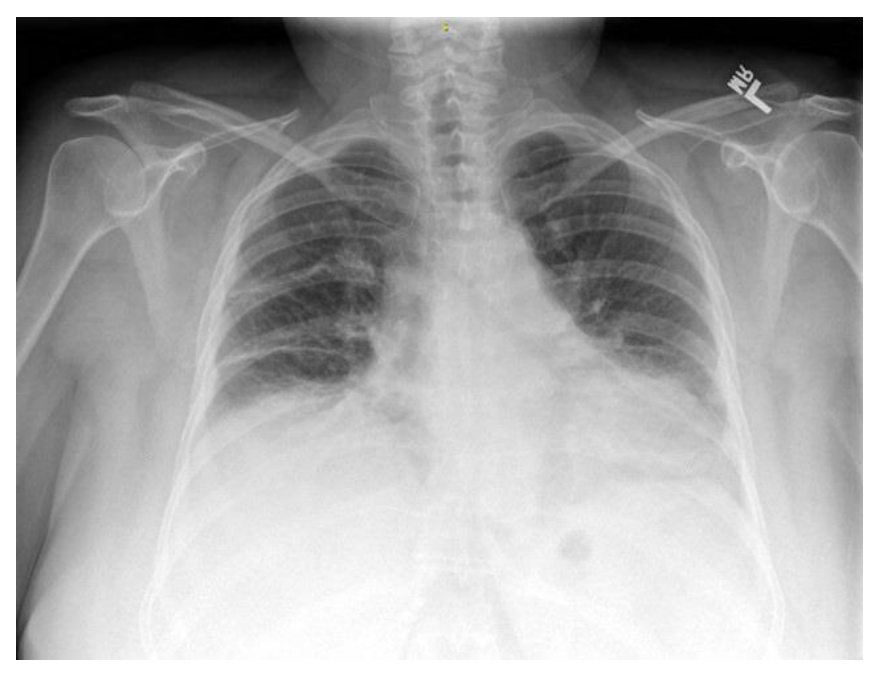

Figure 1. PA chest radiography done on presentation. 
Which of the following should be done?

1. Obtain previous radiography and biopsy reports

2. Pulmonary function testing

3. Thoracic CT scan

4. 1 and 3

5. All of the above 


\section{Correct! \\ 5. All of the above}

Her history, complaints of dyspnea, the presence of crackles on her physical examination and the abnormalities on her chest x-ray all suggest a chronic underlying interstitial process. Her PFTs and CT scan are shown in Figures 2 and 3.

\begin{tabular}{|c|c|c|c|c|c|c|}
\hline \multirow[b]{2}{*}{ - LUNG VOLUMES - } & \multicolumn{2}{|c|}{ PREDICTED } & \multicolumn{2}{|c|}{$\begin{array}{c}\text { CONTROL } \\
\text { Actual \% Pred }\end{array}$} & \multicolumn{2}{|c|}{$\begin{array}{l}\text { POST-DILATOR } \\
\text { Actual \% Chng }\end{array}$} \\
\hline & & & & & & \\
\hline TLC (Pleth) (L) & 5.01 & 4.01 & 2.40 & $=47$ & & \\
\hline $\operatorname{SVC}(\mathrm{L})$ & 3.43 & 2.86 & $=1.42$ & 41 & & \\
\hline RV (Pleth) (L) & 1.75 & 1.40 & $* 0.98$ & $=56$ & & \\
\hline RV/TLC (Pleth) (\%) & 37 & 30 & 41 & 110 & & \\
\hline \multicolumn{7}{|l|}{-- SPIROMETRY -- } \\
\hline FVC (L) & 3.43 & 2.86 & $* 1.37$ & $* 39$ & -1.44 & +4 \\
\hline FEVI (L) & 2.69 & 2.25 & $* 1.16$ & $* 43$ & ${ }^{*} 1.25$ & +8 \\
\hline FEV1/FVC (\%) & 79 & 66 & 85 & 107 & 87 & +2 \\
\hline FEF $25-75 \%$ (U/sec) & 2.60 & 1.43 & $" 1.24$ & -47 & 1.87 & +50 \\
\hline FEF Max (L/sec) & 6.55 & 4.91 & $* 4.63$ & 70 & $* 4.74$ & +2 \\
\hline MVV (L/min) & 100 & 84 & $* 61$ & "61 & & \\
\hline $\mathrm{MEP}(\mathrm{cmH} 2 \mathrm{O})$ & 148 & 124 & 67 & $* 45$ & & \\
\hline $\mathrm{MIP}(\mathrm{cmH} 2 \mathrm{O})$ & -79 & -66 & $*-111$ & $\cdot 140$ & & \\
\hline \multicolumn{7}{|l|}{ - DIFFUSION - } \\
\hline DLCOunc $(\mathrm{ml} / \mathrm{min} / \mathrm{mmHg})$ & 22.21 & 17.77 & *10.95 & 49 & & \\
\hline DLCOcor $(\mathrm{ml} / \mathrm{min} / \mathrm{mmHg})$ & 22.21 & 17.77 & $=11.20$ & $=50$ & & \\
\hline $\mathrm{VA}(\mathrm{L})$ & 5.01 & 4.18 & $* 2.02$ & $=40$ & & \\
\hline \multicolumn{7}{|l|}{ - AIRWAYS RESISTANCE - } \\
\hline Raw (cmH2O/L/s) & 1.86 & 1.55 & $* 1.08$ & *58 & & \\
\hline Gaw (L/s/cmH2O) & 1.03 & 0.86 & 0.94 & 91 & & \\
\hline sRaw (cmH2O*s) & $<4.76$ & 3.97 & 2.08 & & & \\
\hline sGaw $\left(1 / \mathrm{cmH} 2 \mathrm{O}^{*} \mathrm{~s}\right)$ & 0.20 & 0.17 & $* 0.49$ & $=247$ & & \\
\hline
\end{tabular}

Figure 2. Complete pulmonary function tests (PFTs).

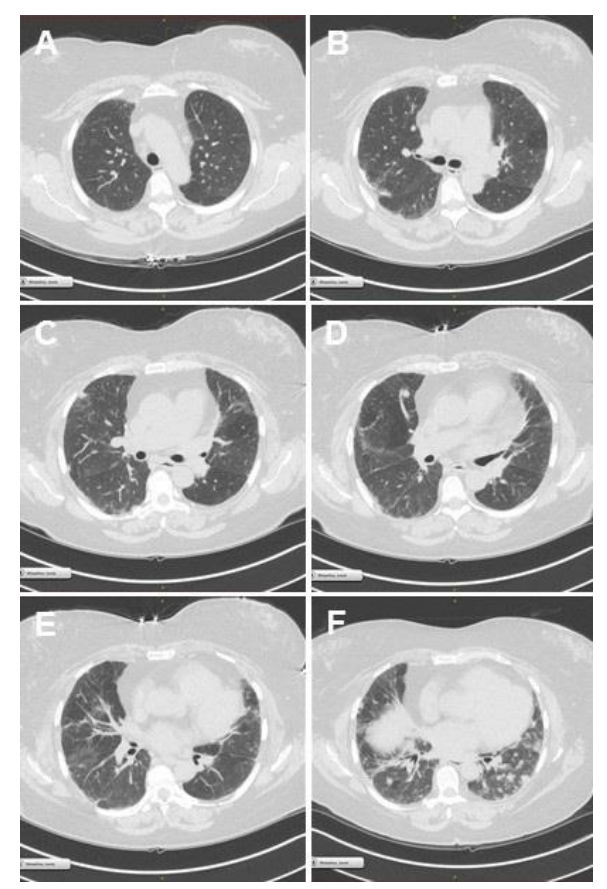

Figure 3. Representative images in lung windows from thoracic CT scan. 
Which of the following are $\underline{\text { true }}$ ?

1. The PFTs show mixed obstructive and restrictive disease and the CT scan shows honeycombing

2. The PFTs show obstructive disease and the CT scan shows emphysema

3. The PFTs show restrictive disease and the CT scan shows a reticulonodular pattern

4. The PFTs show restrictive disease and the CT scan shows honeycombing

5. The PFTs show restrictive lung disease and the CT scan shows emphysema 


\section{Correct! \\ 3. The PFTs show restrictive disease and the CT scan shows a reticulonodular pattern}

The PFTs show a reduced FVC and FEV1 with an elevated FEV1/FVC; reduced TLC; and a reduced $D L C O$. These changes are consistent with restrictive disease.

Obstructive disease is characterized by a reduced FEV1 and FEV1/FVC and usually associated with emphysema on CT scanning.

A rheumatology consult was obtained and felt that the most likely diagnosis was limited systemic sclerosis. Given the uncertain diagnosis to explain her lung findings and the atypical findings for scleroderma-associated ILD, discussed doing another lung biopsy. A decision was made to perform a cryobiopsy and the histology is shown in Figure 4.
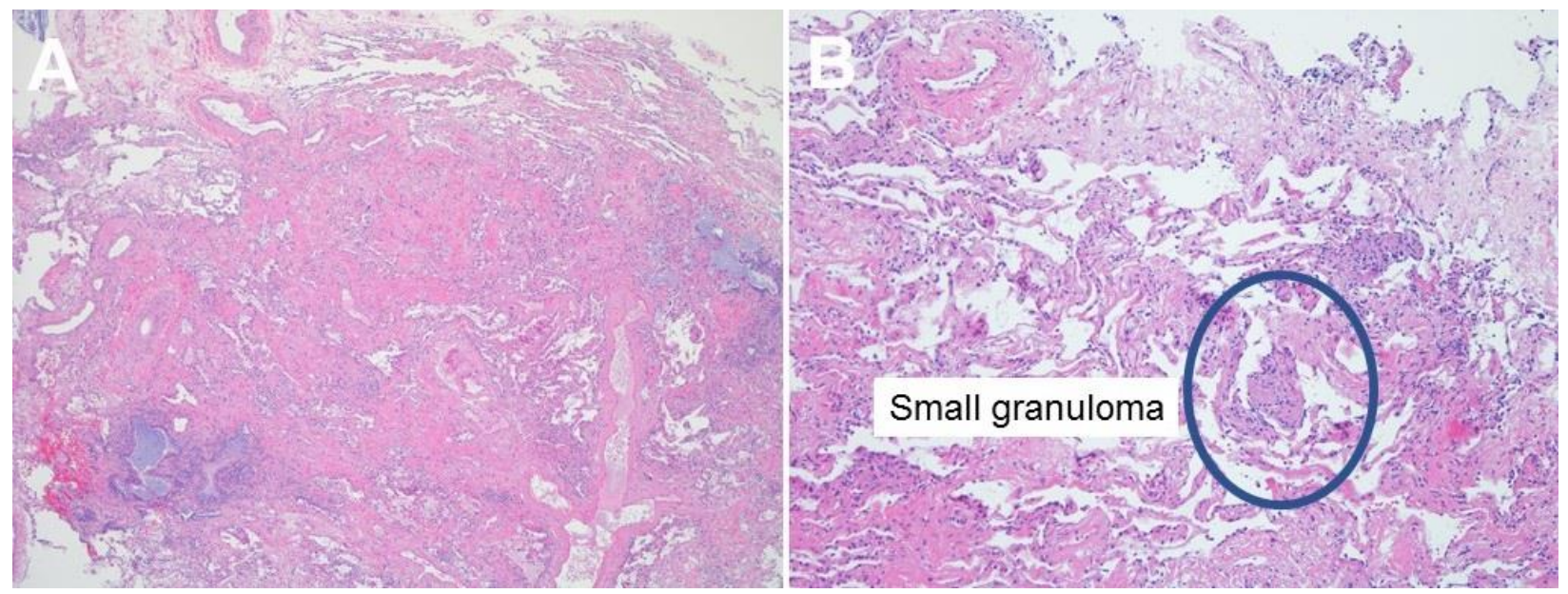

Figure 4. Panel A: Low power view of lung biopsy. Panel B: Higher power view showing a small granuloma.

The pathology report was described as "Patchy mild airway-centered fibrosis with vague non-necrotizing granulomas in airspaces and focally increased eosinophils".

What should be done next?

1. Begin anti-reflux therapy for presumptive chronic aspiration

2. Begin anti-tuberculosis therapy

3. Begin fluconazole for presumptive Valley Fever

4. A or C

5. None of the above 


\section{Correct!}

\section{$1,3,4$ or 5}

A diagnosis can be unclear making the direction to proceed uncertain. This appears to be one of those situations. Granulomata are a nonspecific finding seen with many diseases including infectious diseases (tuberculosis, Valley Fever) and noninfectious diseases (sarcoidosis, aspiration pneumonia). The biopsy really does not establish a diagnosis and treatment for presumptive Valley Fever in the Southwest US or aspiration would not be wrong. The risks of anti-tuberculosis therapy outweigh the chances of her disease proving to be tuberculosis in my opinion. A decision was made to follow the patient. She continued her treatment with azathioprine and was placed on anti-reflux therapy. After 6 months she returned and was feeling increasingly short of breath and her CT scan was repeated (Figure 5).

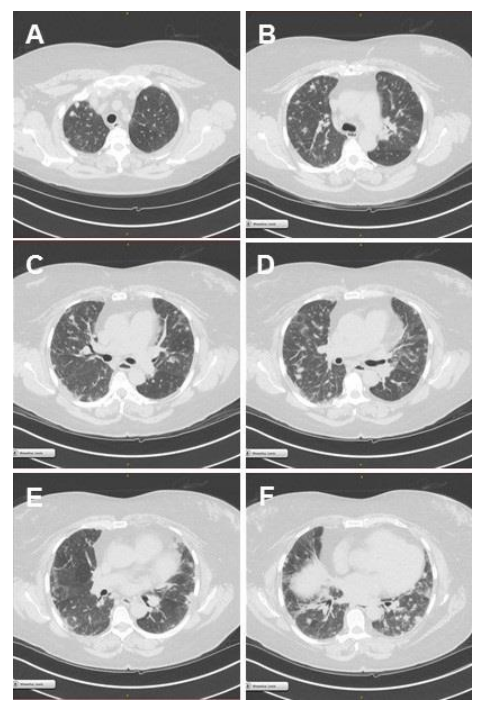

Figure 5. Representative images in lung windows from repeat thoracic CT scan.

The scan was interpreted as showing an increase in the number of nodules. There was some nodularity along pleura and fissures. Some of the nodules contained internal air bronchograms.

Which of the following should be done?

1. A hypersensitivity panel

2. Bronchoscopy with bronchoalveolar lavage and transbronchial biopsy

3. Induced sputum for tuberculosis

4. Video-assisted thoracoscopic surgery (VATS) lung biopsy

5. Any of the above is acceptable 


\section{Correct! \\ 4. Video-assisted thoracoscopic surgery (VATS) lung biopsy}

The description on the repeat CT scan suggests the possibility of a perilymphatic distribution of lung nodules. These often involve the lung lymphatics are seen commonly in sarcoidosis, lymphangitic carcinomatosis, silicosis, coal worker's pneumoconiosis, nodular pulmonary amyloidosis, and lymphocytic interstitial pneumonia (1). Hypersensitivity pneumonitis and endobronchial spread of tuberculosis result in centrilobular distribution (1). None of the possibilities would seem to be easy to sort out without another biopsy.

A VATS biopsy was done and the histology is shown in Figure 6.

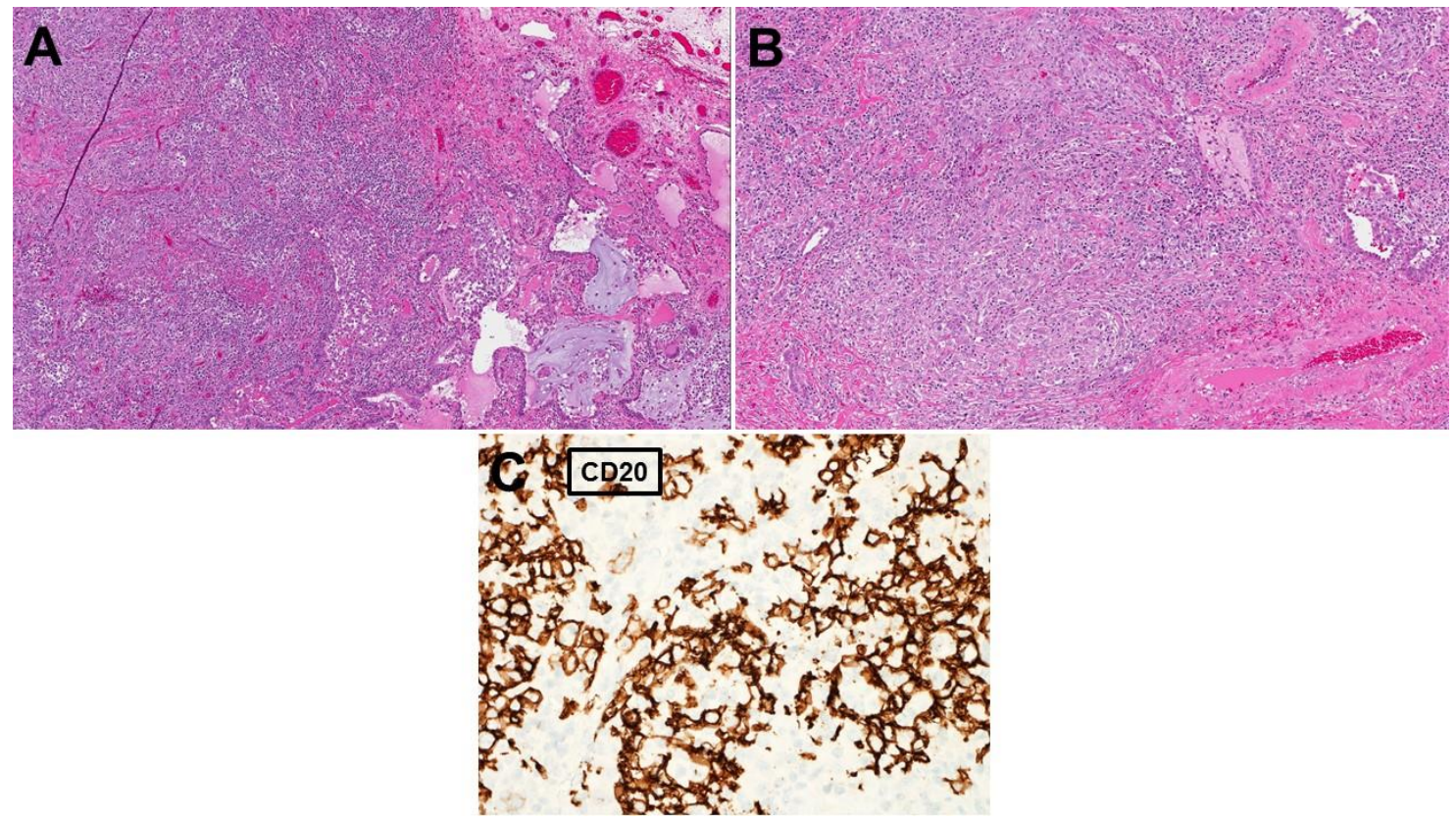

Figure 6. A: Low power view. B. Higher power view. C. Immunostaining with CD20 (B cell marker).

The biopsy was interpreted as showing nonspecific interstitial pneumonia with fibrosis and non-necrotizing granulomatous inflammation. There focal collections of large B cells. Epstein Barr virus staining was negative.

Which of the following is/are the most likely diagnosis?

1. Acquired immunodeficiency syndrome (AIDS)

2. B cell lymphoma

3. Langerhans cell histiocytosis

4. Lymphomatoid granulomatosis

5. Sarcoidosis 


\section{Correct!}

\section{B cell lymphoma}

The patient's disease process falls into the category of lymphoproliferative pulmonary disorders (LPDs). These disorders can be classified into reactive or non-neoplastic and malignant disorders (Table 1).

Table 1. Classification of lymphoproliferative pulmonary disorders (LPDs).

Reactive/non-neoplastic LPDs

- Nodular lymphoid hyperplasia

- Follicular bronchiolitis

- Lymphoid interstitial pneumonia (LIP)

Malignant LPDs

- Extranodal marginal zone lymphoma (MALT)

- Diffuse large B-cell lymphoma

- Lymphomatoid granulomatosis

The reactive LPDs are associated with immunological disturbances and are commonly seen in patients with immunodeficiency or autoimmune disorders. Often these are associated with Epstein Barr virus infection especially in lymphomatoid granulomatosis or AIDS-associated lymphoma.

It is unclear what role azathioprine might have played in this patient's disease process. Azathioprine has been associated with an increased risk of lymphoma but these usually have been associated with Epstein Barr virus infection and treatment for Crohn's disease.

\section{References}

1. Williams KE, Smith ML, Lyng PJ, Vaszar LT. October 2015 pulmonary case of the month: I've heard of Katy Perry. Southwest J Pulm Crit Care. 2015;11(4):126-35. [CrossRef]

2. Hare SS, Souza CA, Bain G, et al. The radiological spectrum of pulmonary lymphoproliferative disease. Br J Radiol. 2012;85(1015):848-64. [CrossRef] [PubMed]

3. Kotlyar DS, Lewis JD, Beaugerie L, et al. Risk of lymphoma in patients with inflammatory bowel disease treated with azathioprine and 6-mercaptopurine: a meta-analysis. Clin Gastroenterol Hepatol. 2015 May;13(5):847-58. [CrossRef] [PubMed] 